\title{
Respiratory Therapy-Driven Protocols: An Important Component to Decrease Overutilization in Medicine
}

Inhaled nitric oxide (INO) is a therapy that causes relaxation and vasodilation of the vascular smooth muscle by stimulating guanylate cyclase and increasing cyclic guanylate monophosphate, leading to a decrease in intracellular calcium. ${ }^{1}$ INO has been found to decrease use of extracorporeal membrane oxygenation and improve outcomes in neonates with pulmonary hypertension. The only U.S. Food and Drug Administration approved indication for INO is in this population.

In this issue of Respiratory CARE, Rogerson and colleagues $^{2}$ present the results of implementation of a singlecenter, hospital-wide, respiratory therapist-driven INO weaning protocol. The authors describe a straightforward weaning protocol based on pulse oximetry and hemodynamic changes including arterial pressure, central venous pressure, and right atrial pressure, if available. Rogerson et $\mathrm{al}^{2}$ elegantly describe their utilization of the Institute for Healthcare Improvement's model for improvement to develop and implement the protocol. Utilizing Plan-DoStudy-Act (PDSA) cycles, the authors first determined the greatest opportunity for improvement surrounded variation in the duration and cessation of INO therapy. In PDSA cycle 2, it was determined the greatest barrier to implementation was poor awareness of the protocol by the medical teams. This realization allowed the study investigators to adjust the implementation plan by including the addition of a laminated bedside card and weekly huddles to improve awareness of the protocol. The successful implementation of the INO weaning protocol led to a $39 \%$ reduction in INO use within 9 months of implementation. This decrease of just over $500 \mathrm{~h} /$ month of INO use hospital wide translated into a yearly cost savings of more than $\$ 900,000$. They are to be commended for their multi-professional approach and the ability to engage leadership across all 3 ICUs.

Use of INO outside of the neonatal pulmonary hypertension population remains controversial. A Cochran review

Dr Todd Tzanetos has disclosed no conflicts of interest. Dr Calhoun has disclosed relationships with Sanofi-Pasteur, the Robert Wood Johnson foundation, and the Society for Simulation in Healthcare.

Correspondence: Deanna R Todd Tzanetos MD MSCI, University of Louisville, 571 S Floyd St, Suite 332, Louisville, Kentucky, 40202. E-mail: drtzan01@louisville.edu.

DOI: $10.4187 /$ respcare. 08742 of INO use in pediatric and adult patients with ARDS did not find any indication for its use in hypoxemic respiratory

\section{See the Original Study on Page 18}

failure. ${ }^{3}$ While transient improvement in hypoxia is often seen, this has not translated to improvements in mortality for patients with ARDS. INO is often used in cardiac ICUs for the management of postoperative patients at risk for pulmonary hypertension or right heart failure. In both instances, studies have failed to demonstrate improvements in outcomes with the use of INO. ${ }^{4,5}$ In fact, some studies suggest worse outcomes when utilized for right ventricular failure in the post cardiac transplant patient. ${ }^{6}$ Despite the lack of evidence, intensivists and neonatologists alike continue to use this therapy for off-label indications. A National Institute of Health statement discourages the routine use of INO in preterm infants, yet a study of neonatologists revealed that use of INO has continued to rise in this population. ${ }^{7}$ In the cardiac ICU, there are relatively few treatment options for right ventricular failure post-transplant. In addition, patients with pulmonary hypertension due to congenital heart disease or chronic lung disease can often be stabilized on INO before being transitioned to long-term therapies such as sildenafil or bosentan. General pediatric intensivists know well the feeling of relief that comes when the saturations increase after INO administration in patients with ARDS. Even if intellectually we know it may not change the outcome, we are relieved by the reprieve and hope that it will buy the patient some time while other therapeutic measures are attempted. We all have an anecdotal story or two of a case where we witnessed sustained improvement in an individual patient who received INO. In my observation, off-label use of INO is unlikely to disappear any time soon.

The unfortunate reality is that utilization of INO is coupled with crippling fees that are often not covered by insurance and are therefore taken as a loss by the hospital system or translated to the patient and their family as a large debt. Give the costliness of INO therapy, it is imperative that we minimize hospital and patient costs while maximizing the freedom of clinicians to do what they feel is right for individual patients. Respiratory therapist-driven 


\section{EDITORIALS}

protocols have been shown to improve costs. Kollef et al ${ }^{8}$ reported that a respiratory therapist-driven assessment and treatment model decreased cost and overutilization of nonstandard therapies with no negative impact on outcomes. Stoller et $\mathrm{al}^{9}$ published results of a randomized controlled trial of physician-directed versus respiratory therapistdirected respiratory care of non-critically ill adult patients. The authors found no difference in mortality or stay but did observe a statistically significant difference in concordance with the standard of care plan from the respiratory therapist-driven group compared to the physician-driven group. In addition, there was a small but not statistically significant decrease in cost in the respiratory therapist-driven group. Todd Tzanetos et $\mathrm{al}^{10}$ presented a respiratory therapistdriven initiation and weaning protocol for INO in a mixed cardiac and medical pediatric ICU. Their study demonstrated a cost savings of approximately $\$ 5,000$ per patient with the use of the protocol. One potential driver for this success is the frequency of assessments afforded to the respiratory therapists. This allows establishment of a baseline and a reassessment after each treatment or wean. This may have the effect of more rapid de-escalation of care due to the comfort that a reassessment will occur relatively quickly. Physician staffing models do not always allow for such frequent reassessments of an intervention, which may foster a less aggressive approach to weaning treatment modalities. In addition, well-written protocols, such as the one presented by Rogerson et $\mathrm{al}^{2}{ }^{2}$ allow for a rapid escalation of therapy if the wean proves to be unsuccessful based on objective clinical findings. This ability to escalate after a failed de-escalation builds in a reliable method for a necessary treatment adjustment that doesn't require immediate physician response.

Utilization of a respiratory therapist-driven protocol to decrease over-utilization of INO and the associated cost is to be applauded. It is important for hospital systems to consider the benefits of respiratory therapist-driven protocols when considering staffing models. Appropriate staffing ratios for respiratory therapists will allow for improved utilization of respiratory care as well as greater adherence to the standard of care for patients with respiratory illnesses amenable to protocol development such as asthma, airway clearance, and the use of INO.

Deanna R Todd Tzanetos Aaron W Calhoun Department of Pediatrics University of Louisville Louisville, Kentucky

\section{REFERENCES}

1. Wang T, Kebir DE, Blaise G. Inhaled nitric oxide in 2003: a review of its mechanisms of action. Can J Anaesth 2003;50(8):839-846.

2. Rogerson CM, Tori AJ, Hole AJ, Summitt E, Allen JD, Samer AS, Valentine KM. Reducing unnecessary nitric oxide use: a hospitalwide, respiratory therapist-driven quality improvement project. Resp Care 2021;66(1): 18-24.

3. Gebistorf F, Karam O, Wetterslev J, Afshari A. Inhaled nitric oxide for acute respiratory distress syndrome (ARDS) in children and adults. Cochrane Database Syst Rev 2016;6:CD002787.

4. Riley CM, Mastropietro CW, Sassalos P, Buckley JR, Costello JM, Iliopoulos I, et al. Utilization of inhaled nitric oxide after surgical repair of truncus arteriosus: a multicenter analysis. Congenit Heart Dis 2019;14(6):1078-1086.

5. Wong J, Loomba RS, Evey L, Bronicki RA, Flores S. Postoperative inhaled nitric oxide does not decrease length of stay in pediatric cardiac surgery admissions. Pediatr Cardiol 2019;40(8):1559-1568.

6. Bearl DW, Dodd DA, Thurm C, Hall M, Soslow JH, Feingold B, Godown J. Practice variation, costs and outcomes associated with the use of inhaled nitric oxide in pediatric heart transplant recipients. Pediatr Cardiol 2019;40(3):650-657.

7. Barrington KJ, Finer N, Pennaforte T, Altit G. Nitric oxide for respiratory failure in infants born at or near term. Cochrane Database Syst Rev 2017;1:CD00399.

8. Kollef MH, Shapiro SD, Clinkscale D, Cracchiolo L, Clayton D, Wilner R, Hossin L. The effect of respiratory therapist-initiated treatment protocols on patient outcomes and resource utilization. Chest 2000;117(2):467-475.

9. Stoller JK, Mascha EJ, Kester L, Haney D. Randomized controlled trial of physician-directed versus respiratory therapy consult service directed respiratory care to adult non-ICU inpatients. Am J Respir Crit Care Med 1998;158(4):1068-1075.

10. Todd Tzanetos D, Housley JJ, Barr FE, May WL, Landers CD. Implementation of an inhaled nitric oxide protocol decreases direct cost associated with its use. Respir Care 2015;60(5):644-650. 